\title{
O regimento contra a pestilência e a receita do bálsamo: alguns comentários à luz da 'medicina científica'
}

\author{
Regime for treating the plague and the prescription of balm: some \\ comments from the perspective of 'modern medicine'
}

Diana Maul de Carvalho

Professora Adjunta, Faculdade de Medicina/UFRJ

Rua Mario Portela, 161/1001 bl. A

22241-000 - Rio de Janeiro - RJ - Brasil

dianamaul@hotmail.com

\section{6)}

CARVALHO, D. M. de.: O regimento contra a pestilência e a receita do bálsamo - alguns comentários à luz da 'medicina científica'.

História, Ciências, Saúde - Manguinhos, Rio de Janeiro, v. 12, n. 3, p. 853-67, set.-dez. 2005.

O Regimento proueytoso contra ha pestenença e o Modus curandi cum balsamo são provavelmente os primeiros textos impressos em Portugal referentes à prevenção e ao tratamento de doenças. Sua autoria e contexto histórico são discutidos em outros artigos desta revista. Destacamos algumas questões relativas ao 'discurso médico' presente nesses textos, contrastando-os com outros do século XVIII. Os autores setecentistas escolhidos são dois portugueses, Luiz Gomes Ferreyra e João Curvo Semmedo, e um inglês, John Huxham, autor de Tratado sobre as febres, que inclui extensa discussão sobre a varíola, a 'pestilência' do século XVIII na Europa. Estas obras, escritas nos primórdios da 'medicina científica', representam, a nosso ver, uma ponte entre os textos medievais/renascentistas e os compêndios médicos atuais. Permitem apontar questões relevantes para a discussão das orientações terapêuticas e dos critérios diagnósticos presentes nos documentos.

PALAVRAS-CHAVE: peste; incunábulos; regimento; doença; história.

CARVALHO, D. M. de.: Regime for treating the plague and the prescription of balm: some comments from the perspective of 'modern medicine'.

História, Ciências, Saúde - Manguinhos, v. 12, n. 3, p. 853-67, Sept.-Dec. 2005.

Regimento proueytoso contra ha pestenença and Modus curandi cum balsamo are probably the first texts addressing the prevention and treatment of diseases to be printed in Portugal. Their authorship and historical context are discussed elsewhere in this journal. Here we would like to raise some questions concerning the 'medical discourse' found in the texts and compare these with others from the eighteenth century. The authors chosen for the sake of comparison are two Portuguese - Luiz Gomes Ferreyra and João Curvo Semmedo - and one Englishman, John Huxham, author of An Essay on Fevers, which includes a lengthy discussion of smallpox, Europe's eighteenthcentury 'plague'. It is our belief that these works, written in the early days of 'scientific medicine', represent a bridge between medieval/Renaissance texts and current medical compendia. They allow us to raise questions about the therapeutic indications and diagnostic criteria found in the documents.

KEYWORDS: plague; incunabula; regime; disease; history. 


\section{Introdução}

O Regimento proueytoso contra ha pestenença e o Modus curandi cum balsamo são provavelmente os primeiros textos impressos em Portugal referentes à prevenção e ao tratamento de doenças e aos agravos à saúde. ${ }^{1}$ A leitura desses 'textos médicos' leva a reflexões sobre alguns aspectos que buscamos apontar neste artigo: por um lado, a própria publicação e seu possível público alvo, assim como o contraste com as formas atuais de divulgação científica; por outro, os conceitos de doença e intervenção terapêutica e suas relações com os conceitos e práticas atualmente vigentes. A origem do Regimento tem sido discutida por diversos autores, ${ }^{2}$ e não vamos argüir aqui seu percurso. Já a receita do bálsamo é de obscura origem. Ambos mereceram ser impressos, contando o primeiro com diversas versões em várias línguas (Roque, 1979). Para nós, representam o discurso médico do final do século XV em Portugal. ${ }^{3}$

Ao ler o Regimento e o Modus curandi, devemos ter em mente que as teorias (e as práticas) hipocráticas vinham se difundindo nas margens do Mediterrâneo, dos séculos VIII ao XIII, principalmente através de autores árabes, destacando-se, a partir do século XII, o grande centro tradutor de Toledo (Cardaillac, 1992). O estudo das sucessivas releituras medievais dos textos gregos e romanos e o estabelecimento dos textos hipocráticos constituem atualmente o objeto de pesquisa de vários autores (Jouanna, 1995). Com o advento da imprensa, algumas obras são especialmente difundidas. A tradução latina do Cânon de Avicena (980-1037) torna-se, nos séculos XV e XVI, a segunda obra mais impressa na Europa, depois da Bíblia (Strohmaier, 1995). E é citado mais de uma vez no Regimento.

Às teorias sobre a doença, a prática médica medieval integrará os conceitos e valores cristãos, charitas et infirmitas, fundamentais para a compreensão de como se devia lidar com a doença e o doente. À relação paternal de Deus com os homens corresponde, no Regimento, a relação fraterna entre os homens. Se amamos a Deus, amamos nossos irmãos. A caridade é a rainha das virtudes teologais (Fé, Esperança e Caridade), e materializa-se na misericórdia e em suas obras: visitar os doentes; dar de beber a quem tem sede; alimentar os famintos; assistir os presos; vestir os nus; acolher os estrangeiros e peregrinos; velar os mortos. A infirmitas iguala doentes, pobres e peregrinos e compreende fraqueza, incapacidade para o trabalho, estado de dependência, falta de estatuto social e dignidade. Cristo é médico e medicamento. A saúde é salus (salus animae) e sanitas (sanitas corporis) (Crisciani \& Agrimi, 1995). A doença é vista como castigo, mas também como provação que pode levar à salvação, à semelhança do que se passou com Cristo. A partir do século XII, o conceito de infirmitas (doença) separa-se cada vez mais do conceito de pauperitas (pobreza). O entendimento da primeira como carência do corpo, temporária, específica, permite agir sobre ela não apenas através da caridade mas também das artes mecânicas (Jacquart, 1995).

O discurso médico consolida um 'regime', isto é, uma série de recomendações para a manutenção da saúde. Bons ares são essenciais para a boa saúde. O odor é uma qualidade fundamental do ar. Incensos e ervas aromáticas o purificam, ajudando a eliminar a pestilência. O campo é visto como menos sadio do que as cidades. Os ventos dominantes do Norte ou do Leste são melhores, mais saudáveis, e por isso convém abrir as janelas para eles. É melhor morar no primeiro andar das casas (nem no porão, nem no sótão). Água com vinagre, com rosas e violetas ou folhas de vinha é fria, refresca o ar. Se este 
está corrompido e há pestilência, é melhor fechar as janelas e queimar incensos. Quanto à alimentação e à digestão, são recomendadas duas refeições por dia, considerando-se mais nocivo o excesso de alimentos que a falta. Legumes quase não constam da alimentação, e só os ricos consomem pão branco, bem como peixes não salgados. No verão, deve-se preferir água fria e, no inverno, água quente (Sotres, 1995).

A peste atinge a Europa em 1347-1348, e muitos autores de então relatam que um terço do mundo morreu. Agnolo di Tura, de Siena, descreve uma cidade onde todos esperam a morte e o fim do mundo. A caridade está morta; os ritos da morte modificamse; o medo facilita o contágio (Grmek, 1995). A medicina propõe medidas de prevenção, geralmente ineficazes. Multiplicam-se as procissões, missas públicas e romarias de penitentes (Sournia \& Ruffie, 1984). Difundem-se as medidas de isolamento e quarentena. Herlihy (1997) analisa as causas e conseqüências da peste na Europa; com base em estudos de cemitérios em Pistóia, nega a explicação malthusiana, segundo a qual a epidemia seria conseqüência de aumento da fecundidade com aumento da população. O quadro explicativo de Herlihy dá ênfase a fatores sociais, políticos e econômicos: não apenas superpopulação, mas também monocultura do trigo, excesso de taxação dos pobres, má qualidade de vida.

Ao se propor científica, no século XVIII, a prática clínica, diagnóstica e terapêutica continua a se fundamentar na teoria dos humores, ainda que modificada pelos iatrofísicos e iatroquímicos, que tentam incorporar ao discurso médico o discurso científico da época (Haller, 1761; Broussais, 1828). Assim, ao lermos os textos medievais e os confrontarmos com os setecentistas, devemos ter em mente que representam sucessivas releituras de um mesmo 'discurso sobre a doença', em contextos históricos diversos. O contraste que faremos dos dois textos ora reproduzidos com outros do século XVIII, visa identificar que soluções foram adotadas para satisfazer a crescente necessidade de incorporar o discurso científico do século das Luzes às teorias mais antigas sobre saúde e doença, e às justificativas das práticas terapêuticas. Estamos pouco mais de um século distantes da solução proposta por Claude Bernard - o 'meio interno' - conceito que tornaria possível o discurso fisiológico e incorporaria as teorias da física e da química às ciências da vida (Bernard, 1911 [1865]).

Os textos dos portugueses Luiz Gomes Ferreyra e João Curvo Semmedo são anteriores às reformas pombalinas ${ }^{4}$ mas, em sua estrutura e conteúdo, já refletem o propósito de incorporação de conhecimentos científicos. O texto de John Huxham (1757) revela, também, a preocupação do autor em se ater aos fatos e à experiência, marcas da ciência. Os três textos fazem recomendações diagnósticas e terapêuticas para lesões traumáticas e para as pestes de sua época, as febres e a varíola. Buscaremos, aqui, identificar semelhanças e contrastes com os textos medievais/renascentistas.

Para comentar as receitas do bálsamo, referimo-nos com freqüência à edição facsimilada organizada por João Rui Pita, da Pharmacopea Lusitana (Santo Antonio, 1704). Originalmente editada por D. Caetano de Santo Antonio, em 1704, trata-se da primeira farmacopéia portuguesa. Interessou-nos sobremaneira para a discussão de nossos textos não só por representar uma síntese dos medicamentos em uso em Portugal no início do século XVIII, como porque o autor comenta os Cânones de Mesue, apresentando tanto as suas receitas como as de Galeno e outros autores que constituem a base da terapêutica medieval. ${ }^{5}$ 
Além da Pharmacopea, utilizamos a edição de 1548 de Pietro Andréa Matthioli, da Materia Medica de Dioscórides (séc. I?). Essa segunda edição é ampliada em relação à de 1544, contendo o sexto livro, que não consta da primeira.

Para a discussão do Regimento, além das obras mencionadas, utilizamos também cópia da versão inglesa de Thomas Paynel (1534), cujo original está depositado no British Museum, em Londres.

\section{Os textos e sua divulgação}

O século $X X$ consagra, no ensino médico, a utilização de compêndios de clínica e terapêutica reservados à leitura dos professores e alunos. A divulgação de 'conhecimentos médicos' para os leigos fica reservada a publicações com esse fim explícito, que não são leitura para 'especialistas'. Essa tendência à compartimentalização dos conhecimentos toma impulso a partir do século XVIII com a definição da prática médica de base científica, e gera numerosos tratados de médicos para médicos e, paralelamente, de médicos para leigos, contribuindo para a 'educação do povo'. São espaços estanques, somente transpostos pelos próprios médicos. ${ }^{6} \mathrm{~A}$ divulgação para leigos dá origem a publicações bastante populares nos séculos XIX e XX. No Brasil, uma das mais conhecidas é o 'Chernoviz', ${ }^{7}$ que não podia faltar nas casas de fazenda. O movimento higienista deu grande impulso a essa forma de 'educação popular', gerando publicações destinadas a grupos especialmente visados pelos médicos como agentes da prevenção das doenças. Bom exemplo é A Mai de Família, revista publicada no Rio de Janeiro a partir de 1878 pelo médico Carlos Costa. ${ }^{8}$ Até o século XVIII, essa separação do conhecimento parece não ser nítida, e temos vários exemplos tanto da incorporação dos conhecimentos 'populares' imediatamente aos textos médicos, quanto da variedade de destinatários dos tratados de medicina. ${ }^{9}$

Assim, no Erário Mineral de Luis Gomes Ferreyra (1735), cirurgião português que por vinte anos praticou medicina no Brasil, na região das Minas Gerais, há uma receita para tratamento das lesões da varíola que Curvo Semmedo teria recolhido em Portugal, de um 'rústico' (p. 130). De fato, na Atalaia da vida contra as hostilidades da morte (Semmedo, 1720, p. 81), esse médico da Casa Real portuguesa endossa a receita recolhida "de um homem rústico": "frigireis quatro ou seis lagartixas vivas em meia canada de azeite velho, até que as lagartixas se torrem..." (p. 81).

Ao dedicar sua obra a Jesus Crucificado, João Curvo Semmedo torna explícito que "o principal motivo de a fazer é acodir aos pobres enfermos faltos de médicos, ou de cabedaes para os chamar" (dedicatória, sem número de página). E ressalta a importância, para esse fim, de publicar em português. Também Gomes Ferreyra deixa claro que seu públicoalvo não é constituído exclusivamente por médicos e cirurgiões (Ferreyra, 1735).

Os textos aqui comentados foram publicados um em português, o outro em latim. Podemos supor que daí decorre uma diferença no público a que se destinavam? Parece que sim.

O Regimento, com versões em várias línguas, e já centenário quando publicado em português, buscava atingir um público mais amplo que o dos médicos, ainda que restrito aos alfabetizados. A crise provocada pelas epidemias de peste no século XIV, na Europa, no norte da África e no Oriente Médio gerou novas formas de intervenção para o controle de doenças, ensejou a revisão do conceito de contágio pelos autores árabes, e, 
certamente, diante da carência generalizada de médicos, tornou ainda mais necessária a difusão das causas da peste e das formas mais indicadas para tratar suas vítimas (Strohmaier, 1995).

Já o bálsamo para ferimentos resultantes, principalmente, de traumatismos parece ser um texto voltado para os praticantes da arte de curar. Não somente os físicos e cirurgiões, mas todos aqueles que estivessem capacitados a distinguir os vários tipos de ferimentos e sua relativa gravidade. Requer o conhecimento dos componentes das receitas, das formas de os manipular, dos pesos, medidas e instrumentos adequados para se chegar a produzir o medicamento. Publicado em latim, teria, já no século XV, possivelmente um público mais restrito.

\section{O Modus curandi cum balsamo}

O bálsamo aqui descrito é um medicamento composto ${ }^{10}$ (a composição não é explicitada) com propriedades cicatrizantes. As indicações de uso referem-se em especial às feridas traumáticas, mas não exclusivamente, já que o medicamento também é indicado para ulcerações na boca. É interessante notar que ao uso tópico sob forma de ungüento se adiciona a indicação de ingestão (lat. "per os") no caso de feridas penetrantes, para que o medicamento possa atingir a porção mais interna da lesão e exercer sua ação cicatrizante. De modo análogo, quando se trata de lesão na boca, o indicado é o gargarejo.

A aplicação do bálsamo só deve ser feita quando o ferimento está em fase de cicatrização, sem complicações. Assim, a dor, quando ocorre, deve ser tratada do modo habitual, com outros medicamentos que o autor não menciona, mas diz serem os de uso comum. Da mesma forma, se o ferimento for profundo ou houver fratura, antes da aplicação do bálsamo são indicados os procedimentos habituais do cirurgião. Em caso de febre, indicase a sangria.

A primeira receita, para beber, mistura o bálsamo com xarope ${ }^{11}$ de viola e endívia e água bugulosa, e aconselha seu uso diário ao nascer do sol.

D. Caetano de Santo Antonio (1704), ao comentar os Cânones de Mesue, traduz endívia (lat. med. endiuia/endibia) por 'almeirão doméstico'. As violas ou violetas são componentes de inúmeros medicamentos. Quanto à bugulosa ou buglossa, o mesmo autor a identifica como 'língua de vaca' e publica a receita de seu xarope de acordo com Valério Cordo (succus buglosae quomodo extrahitur). Já Andrea Matthioli (1548), em seus comentários à obra de Dioscórides (séc. I?), considera que a buglossa, pela semelhança com o verbasco, como descreve Dioscórides, é a borragine ou borragem, e diz ser mencionada também por Avicena e Galeno. Transcrevemos o que diz Dioscórides (1548) sobre a buglossa:

Nasce la Buglossa nelle planure, \& ne i luoghi arenosi. Cogliesi il me di Luglio. Dicono, che quella, che produce tre fusti, tritandoci com il suo semo, \& com la sua radice, giova beunta cõtra al rigore della febbre terzana, \& quella, che ne produce quattro, cõtra à quelli delle quartane, suocesi nel [ilegível]. Dicono essere questa utile anchora alle posteme. É simile al verbasco, \& produce la sue frõdi sparse per terra, le quali sono nere, \& aspre similia alle lingue de i buoi. Messe le frondi nel vino, allegrano \& consolano l'anime. (p. 592) ${ }^{12}$ 
Tanto as flores da buglossa como as violas são listadas na Pharmacopea Lusitana (Santo Antonio, 1704) como flores cordiais; já o almeirão é uma das sementes frias menores. As violas devem ser colhidas cedo pela manhã, ainda segundo a Pharmacopea, antes que o calor do sol dissipe suas virtudes. O Modus curandi recomenda que o remédio seja tomado ao nascer do sol. A receita parece garantir o equilíbrio entre as propriedades cordiais e frias de seus componentes.

A segunda receita, para uso externo, diz respeito a um composto cuja finalidade é permitir a recuperação de ferimentos na cabeça que tenham penetrado a dura mater. $\mathrm{O}$ óleo 'infancino', provavelmente é o 'óleo omphancino' citado na Pharmacopea lusitana: vem a ser "azeite de azeitonas imaturas" (p. 310). O mel rosado é preparado com mel e sumo de rosas em partes iguais, cozinhando-se a mistura até se obter ponto de mel; em seguida, é coada e guardada para o uso, em vidro, pondo-se-lhe em cima algumas gotas de óleo rosado. Assim ensina a Pharmacopea (p. 109).

A terceira receita apenas orienta a mistura do bálsamo com água de rosas, que é componente de muitos remédios, considerada por Mesue como 'remédio bendito' (Santo Antonio, 1704). Era usada nesse caso para tornar o gargarejo agradável e reconfortante.

Qual seria a composição do bálsamo básico?

$\mathrm{Na}$ Pharmacopea Lusitana, encontramos mais de uma vez a receita básica de Galeno para os ungüentos: quatro partes de azeite para uma de cera (de abelhas). São referidos também vários ungüentos contendo (como excipiente?) gorduras de origem animal e clara de ovo. As receitas de Semmedo e Gomes Ferreyra acrescentam várias ervas mantendo os óleos, gorduras e claras de ovos. Esses autores, com freqüência, incluem também em suas receitas compostos minerais que provavelmente não eram de uso no século XV (Pita, 2000).

Antes de apresentar suas receitas de bálsamos compostos de óleos e ervas, Curvo Semmedo (1720) descreve as virtudes da Balsamina, erva a que atribui notável poder de cicatrização:

Não se pode encarecer a estupenda virtude, que esta maravilhosa erva tem, porque se cortarem o nariz a um negro, e no mesmo tempo cortarem o nariz a um homem branco, e ajuntarem o nariz do negro ao nariz do branco, e os polverizarem com o pó desta erva, soldará de sorte, como se fosse o nariz da mesma pessoa, sem ficar sinal de costura. (p. 73)

Apesar das repetidas afirmativas de que as receitas selecionadas são fruto de quarenta anos de observações práticas, é difícil imaginar tal transplante bem sucedido. Antes, deve-se supor que o relato é uma hipérbole destinada a sintetizar as impressões do autor a respeito do medicamento. Infelizmente, não há informação suficiente para a identificação da erva. O bálsamo que Semmedo indica para curar feridas, inclusive da cabeça, e mesmo quando há fratura, é composto por elementos minerais e azeite velho, e a balsamina não retorna nas várias formulações que se seguem no livro. Em comum com o Modus curandi, recomenda esse autor que não seja usado sobre a lesão aberta: "a regra geral para usar deste grande bálsamo é, que se unte a parte dolorosa, mas não a ferida" (p. 76).

No Erário Mineral (Ferreyra, 1735), encontramos uma receita com propriedades cicatrizantes que se assemelha ao bálsamo básico de Semmedo: "Cera branca três onças, alvaiade em pó sutil seis onças, óleo rosado doze onças, claras de ovos número três, alcanfor uma oitava, tudo se misture, e cosa a fogo brando até tomar consistência de ungüento, e em falta de óleo servirá azeite doce" (p. 125). 
A balsamina talvez represente uma recordação da planta do bálsamo, descrita por Dioscórides (séc. I?) como um arbusto sempre verde, que nasce somente na Judéia e em certo vale do Egito. Deste arbusto colhe-se uma seiva denominada Opobalsamo. Outras plantas produzem sumos semelhantes (xilobálsamos), que servem para purgar úlceras, provocar diurese, facilitar o parto, curar mordidas de serpentes e ferimentos na cabeça. O texto atribuído a Dioscórides traz o relato de inúmeras falsificações, especialmente misturas contendo cera líquida e outros ungüentos, afirmando o médico de Anazarbo que o bálsamo verdadeiro é muito caro. A planta quase milagrosa nas suas múltiplas indicações já não parece ser familiar a Matthioli (1548), que relata a evolução do bálsamo para os vários compostos com indicações semelhantes e com características de óleos e ungüentos em uso no seu tempo.

Nos trezentos anos que separam o Modus curandi dos autores setecentistas foram acrescentados alguns 'simples' aos possíveis candidatos a componentes dos medicamentos, mas os princípios gerais da terapêutica não mudaram. Em relação ao trauma, só mudarão radicalmente no século $X X$, com a universalização da anestesia e, em conseqüência, da grande cirurgia; dos raios $X$, que permitem acompanhar a evolução das fraturas e outras lesões; e ainda das medidas de controle das infecções. Deus é louvado nas três obras do século XVIII, mas sua atuação é revelada aos homens através de remédios com muitas virtudes curativas. Resultado de ações e interações humanas, o trauma é, desde sempre, socialmente determinado, e sua prevenção está primariamente na esfera do humano.

\section{O Regimento proueytoso contra ha pestenença}

O Regimento inicia-se com uma prece: "Ora pro nobis sancta dei genitrix. Ut mereamur peste epydimie illesi transire et promissionem Christi optinere" (Ora por nós Santa Mãe de Deus. E nos torne merecedores de atravessar ilesos a epidemia de peste e dignos das promessas de Cristo). Curvo Semmedo diz que "o mais seguro prezervativo, \& curativo da peste, são as confissões com verdadeyro arrependimento das culpas, as Orações, os jejuns, \& as penitencias, \& recorrer a Deos, tomando por intercessora a Santíssima Virgem Maria Mãy de Deos, \& Advogada dos peccadores, cantando-lhe a seguinte Antiphona". Da oração que se segue, destaca-se o apelo: "Ora pro nobis Santa Dei genitrix. Ut digniefficiamur promissionibus Christi" (Ora por nós Santa Mãe de Deus. E nos torne dignos das promessas de Cristo, p. 522). Por quatrocentos anos ressoa o mesmo apelo como o primeiro remédio, ou o mais seguro, contra a doença pestilencial.

Já o Erário Mineral (Ferreyra, 1735) e o tratado de John Huxham (1757), ainda que tratem de doenças epidêmicas, não mencionam a peste nem orações com poder de cura. As epidemias do Erário são principalmente as pleurisias e peripneumonias atribuídas ao frio e à umidade da região das Minas Gerais. As de Huxham são as muitas febres e, principalmente, a varíola e uma forma de angina possivelmente diftérica. Escrevendo sobre sua prática de mais de quarenta anos, Semmedo (1720) provavelmente reflete ainda o impacto das últimas devastações da peste na Europa, no século XVII. Tal suposição é reforçada por sua menção à epidemia de 1631 em Niza [Nice], no litoral da Provença, fornecendo Semmedo a receita do 'antídoto d'El Rei Mitridato', excelente "contra veneno e principalmente para o tempo da peste" (p. 521). Ele também publicou, em 1680, um tratado sobre a peste que, segundo o próprio autor, tornara-se uma raridade em 1720: 
"porque se gastarão os que imprimi" (p. 522). Efetivamente, não conseguimos localizar exemplares desse tratado.

O texto do Regimento, após as introduções e dedicatórias de praxe, está dividido em cinco capítulos: 1) dos sinais prognósticos da pestilência; 2) das cousas dela; 3) dos remédios dela; 4) das conformidades do coração, e dos principais membros; e, por fim, 5) da sangria.

Os sinais prognósticos antecedem a descrição dos sinais e sintomas que permitem o diagnóstico, e a organização segue a teoria hipocrática, apontando fatores de desequilíbrio do meio ambiente favoráveis ao aparecimento de doenças epidêmicas (Littré, 1839-1853).

\section{Dos sinais prognósticos}

O autor do Regimento inicia sua exposição discutindo os sinais prognósticos da 'peste', atribuindo a mudanças climáticas e ao movimento dos astros influências mediatas e imediatas sobre o equilíbrio dos organismos vivos e sobre a saúde humana. Longe de representar uma visão 'mágica' ou 'supersticiosa', como se tem muitas vezes dito (Cornford, 1981), o desenvolvimento da pestilência é apresentado de forma ordenada e coerente a partir dos elementos explicativos da ocorrência das doenças, ou seja, o desequilíbrio das características, da quantidade e do fluxo dos humores que constituem o organismo humano (Cairus \& Ribeiro, 2005). ${ }^{13}$ Esse organismo, que integra o mundo imediatamente, não possui meio interno, não mantém ainda nenhuma ligação com a fisiologia do século XIX. Pode ser, assim, imediatamente modificado por alterações dos elementos do universo. Não apenas pode, como é difícil imaginar que escape ileso a tais influências, a não ser por 'milagre' ou 'magia'.

O autor aponta os sete sinais que concorrem para o desequilíbrio geral: o verão com névoa matinal dispersada pelo vento do sul; os dias (de verão) nublados mas sem chuva; as moscas, que sinalizam o ar peçonhento; cometas; relâmpagos, trovoadas e muito vento vindo do sul. No texto ora reeditado são relatados apenas seis sinais. No entanto, a versão inglesa (Paynel, 1534), que Keiser (2003) considera como originária da mesma versão primordial, traz a descrição de sete sinais. A diferença reside nas estrelas cadentes, que não são mencionadas no nosso texto:

The fourthe is, whan that the starres do apere and seme to fall, and departe fro their places: the whiche thinge dothe also signifie, that the aire is infectyd and charged with infectyd and poyson vapours. (Paynel, 1534, $\left.\left[2^{\mathrm{v}}\right]\right)^{14}$

Os sinais, a ênfase no vento sul, sugerem um verão quente, de atmosfera 'pesada' úmido? seco? - um verão excepcional. O cometa parece contribuir apenas como agravante da intensidade do fenômeno.

Hoje, prognóstico é coisa bem diversa, uma vez que a fisiologia de Claude Bernard se tornou o quadro teórico hegemônico para explicar a ocorrência das doenças. O prognóstico passou a significar, exclusivamente, o mais provável percurso da doença no indivíduo, perdendo sentido a 'conjuntura epidêmica'. O prognóstico não se refere mais aos lugares e ao coletivo, e sim a cada indivíduo. Só é coletivo por referência a grupos de indivíduos, 'grupos de risco'. E não mais precede logicamente (ainda que possa fazê-lo cronologicamente) o diagnóstico, mas, necessariamente lhe sucede, e dele 
depende. O meio externo desaparece como dimensão necessária do discurso médico. Recua e se transforma em paisagem, pano de fundo. O organismo e as alterações anátomofisiopatológicas assumem o centro do discurso médico sobre a doença (Canguilhem, 1990). O diagnóstico da doença e do doente é o momento inicial.

Assim, o capítulo 1 do Regimento proveytoso contra ha pestenença não é mais inteligível para médicos e passa à categoria de 'curiosidade'. O discurso atual encontra mais afinidade com o capítulo 2 .

\section{Das causas}

O autor continua a falar do 'ambiente' e de sua influência sobre as doenças, mas há sutis diferenças. Aqui não se fala mais das grandes alterações do movimento e da composição dos ares, das águas, sequer dos lugares. Fala-se de um 'ambiente' que hoje, mediado pela teoria dos germes, integra nosso discurso sobre as doenças.

Para o senso comum, o discurso do século XIV não parece mágico ou supersticioso mas tão somente 'ingênuo', 'ignorante'. Os germes ainda não eram conhecidos; Pasteur e Koch nem tinham nascido. Mas conseguimos entender o que está sendo dito e 'traduzir' isso para a linguagem científica atual. Afinal, os corpos mortos, os chafarizes sujos, os charcos e as privadas ocultam agentes e vetores de doenças. Onde se fala das emanações dos pântanos, enxergamos mosquitos voando e parasitas; nos chafarizes, nas fezes, nos corpos, vemos vírus, bactérias; por toda parte, infecções. Isto principalmente quanto aos males que têm causa na raiz inferior. ${ }^{15}$

Aponta o autor do Regimento, neste capítulo, duas questões notáveis: por que morrem alguns e outros não? E se são contagiosas as pestilências.

A resposta à primeira pergunta envolve questões similares às do prognóstico atual, nomeando o autor os mesmos tipos de fatores que o determinam hoje, concernentes ao agente e ao paciente: “Da parte do agente quando aquela influência sobre celestial mais direitamente fere e esguarda aquele ou aqueloutro, que aquele ou aqueloutro lugar ou homem. Da parte do paciente que aquele é mais disposto à morte que aqueloutro...".

Os agentes são outros, mas a intensidade de sua ação pode ser facilmente 'traduzida' para o discurso atual sobre a virulência: o paciente morre por fatores de risco 'constitucionais', idade, sexo etc. Na perspectiva do Regimento: por ter o corpo quente, excesso de humores, poros excessivamente abertos ou fechados, praticar sexo ou banhos em excesso etc.

Quanto à questão da contagiosidade das doenças pestilenciais, afirma o autor que "dos corpos apeçonhentados procedem humores e fumos peçonhentos que corrompem o ar". Seguem-se as medidas para evitar o contágio: fugir das aglomerações e do contato com doentes, assegurar ventilação adequada, precaver-se contra o vento sul.

Huxham (1757) reafirma que as febres pestilenciais e petequiais originam-se do contágio e "podem portanto afetar pessoas de todas as constituições, o que produzirá, é claro, grande variedade de sintomas" (p. 93). ${ }^{16}$

Também Semmedo (1720) considera as febres malignas transmissíveis pelo 'bafo do doente'. Recomenda medidas para purificar o ar da casa do enfermo, e acrescenta interessante comentário sobre as possibilidades do contágio: 


\begin{abstract}
Algumas febres malignas, e outras doenças perigosas sobrevêm muitas vezes aos corpos das pessoas que comeram carne de alguma rês, ou animal, que está enfermo, ou morreu de doença, e daqui fiquem advertidos os donos dos tais animais, que façam grandíssimo escrúpulo de os vender para que se comprem no açougue; e o mesmo escrúpulo devem fazer as galinheiras para não venderem galinhas, perus ou cabritos, que estão doentes; porque a doença daquele boi, porco, ou qualquer outra rês que estão enfermos se comunica, e transplanta naquelas pessoas, que comeram as tais carnes... (p. 265)
\end{abstract}

\title{
3. Dos remédios
}

Coerentemente com o quadro teórico da época, os remédios incluem medidas preventivas e curativas em interação continua, parecendo evidente que não faz sentido separálas pois atuam sobre os mesmos fatores básicos.

A prevenção inicia-se com medidas para facilitar a intervenção divina, única capaz de evitar totalmente os efeitos da conjuntura pestilencial.

Afastar-se do local atingido pela peste é a recomendação seguinte. Mas se compreende que muitos não podem fazer isso. Deve-se, então, evitar a exposição aos 'fatores de risco': excesso de luxúria, vento sul, fedores, excesso de alimentos, banhos e aglomerações. Para evitar que a casa se contamine, acenda-se o fogo que purifica o ar, queimem-se ervas aromáticas e lave-se a casa com vinagre e folhas de uva. As medidas de proteção individual incluem alimentos adequados, nunca em excesso. $\mathrm{O}$ autor atribui a Avicena a advertência de que "aqueles que sempre querem encher seus ventres, abreviam seus dias". Lavar freqüentemente as mãos e o rosto com água e vinagre e evitar todo fedor diminuem as chances de que a peçonha invada o organismo. Apesar do título, o capítulo não menciona remédios para tratar os doentes. Toda a ênfase está em se evitar a 'peçonha', pois quando ela se instala, pouca esperança resta.

Ao discutir a peste de seu tempo, a varíola, John Huxham (1757) faz advertências preventivas semelhantes, mas então, tanto para a prevenção como para o tratamento, a 'constituição' de cada paciente é tão importante quanto a 'constituição' do ar:

A particular Regard then must be had to the Constitution of the Patient, and the Constitution of the Air, if we would practise with Reason and Success in the Smallpox, and indeed in all other epidemic Disorders. (p. 134) ${ }^{17}$

A variedade das situações é enfatizada, questionando o autor a noção predominante de que para cada tipo de doença está indicado um regime específico, sem consideração do paciente:

In a Word, the particular Case requires a particular Method, and the attending Physician is to shew his Judgement in adapting it rightly. (p. 128) ${ }^{18}$

Em Luis Gomes Ferreyra (1735) percebe-se também a crescente rebeldia em relação aos 'autores antigos' e a necessidade de observar e levar em consideração as diferenças entre as constituições de pacientes e climas: "com tudo a experiência nos mostra, que não há no mundo cousa alguma tão certa, nem tão infalível, que não tenha suas exceções, e deixe de faltar algumas vezes" (p. 2). E logo adiante: "Diz mais o sobredito Hipócrates, que os empiemáticos, e os que têm matérias supuradas dentro do vão do peito, só se purgam, e evacuam por escarro; e a experiência tem mostrado, que escaparam alguns, 
deitando as matérias já por via das ourinas, já misturadas com a câmera" (p. 3). Seguemse vários capítulos em que o autor reitera a necessidade de considerar a especificidade do clima e dos hábitos das Minas Gerais ao se aplicarem medidas preventivas e tratamentos, especialmente em relação às pontadas pleuríticas, "o flagelo que mais tem destroçado os mineiros destas Minas" (p. 1).

\section{Das conformidades do coração e dos outros membros}

A influência do Cânon de Avicena é evidente não apenas em virtude das citações feitas ao longo do Regimento como pela primazia dada ao coração no título deste capítulo. Sendo o primeiro órgão a se formar, produz o sangue e distribui pelas artérias o pneuma vital; portanto sua 'conformidade' é fundamental para o equilíbrio que constitui a saúde.

A tanchagem ou chantagem é uma das ervas frias principais (Santo Antonio, 1704); a Cassia Fístola é de propriedade temperada a quente, e solutiva (Orta, 1891 [1563]); o açafrão é "cordial e abridor" (ibidem). A recomendação destas ervas indica, mais uma vez, a preocupação com o equilíbrio dos humores para evitar a pestilência. Contra a peste Orta receita ainda as pílulas de Rasis (Rhazes) compostas por açafrão, aloés e mirra. Possivelmente, são as mesmas "pirolas pestilenciais" mencionadas no Regimento.

Para impedir o contágio da peste, este último texto reitera a importância de se evitar "o bafo de outrem", de usar-se preventivamente a água de rosas ou vinagre para lavar a boca, os olhos e as mãos. A boa alimentação é fundamental e, como a peste é favorecida pelo aquecimento e ressecamento dos humores, devem ser evitados alimentos e bebidas quentes e secos, inclusive todos os frutos que não forem azedos. As especiarias devem trazer o equilíbrio, o tempero. É recomendado manter-se o fogo aceso em casa para purificar o ar, e o uso de clisteres para manter-se a evacuação regular. Por fim, lembra o autor do Regimento que a alegria do coração e o bom humor são fundamentais para a saúde do corpo; para manter o equilíbrio que evita a peste.

O uso do vinagre como preventivo é recomendado por Semmedo: "Também conduz muito untar com o dito vinagre os narizes, as fontes da cabeça, e os pulsos dos braços" (p. 521). Os purgantes permanecerão até o século XX como um dos meios privilegiados de eliminação dos humores em excesso, dos venenos, do contágio. Huxham (1757) afirma que por mais de uma vez viu pacientes serem salvos da morte por varíola graças a diarréias espontâneas ou provocadas por medicamentos.

\section{Da sangria}

O Regimento contém afirmações genéricas em relação ao uso das sangrias, à periodicidade ("uma vez em um mês, se pode bem fazer"), e às restrições por idade ou condição especial (gravidez, fraqueza extrema). Recomenda ainda que a sangria seja feita antes das refeições, e que depois se tome vinho ou cerveja. No entanto, após a operação não se deve dormir, como também aqueles que são atingidos pela peste não devem dormir, pois isto permite o alastramento da pestilência no organismo. O risco é tão grande que o sono deve ser evitado a todo custo, pelo menos até uma hora após as refeições, quando à quentura intrínseca do sono se acrescenta a da digestão, com possíveis conseqüências graves.

A recomendação da sangria é radical, "até esmorecer", sabendo-se que a pouca saída de sangue piora o quadro da doença. A operação deve ser próxima à lesão pestosa e em 
veia homolateral, se o paciente não dormiu após o início dos sintomas. Se dormiu e acordou com as lesões, a sangria deve ser contralateral. ${ }^{19} \mathrm{E}$ não se deve permitir que durma antes do meio-dia. Depois disso, o bubão poderá lançar fora o mal e o paciente se recuperará. Para madurar mais rapidamente o bubão, usam-se emplastros de folhas de sabugo e mostarda, ou de avelãs, figo e arruda; ou ainda, para beber em jejum, suco de barba-jovis, siligem (trigo) e tanchagem, misturados com leite humano. Termina o Regimento com essas recomendações e com os louvores de praxe a Jesus Cristo e à Virgem Maria. A versão inglesa, de Thomas Paynel, continua com dois pequenos textos, um sobre as urinas e outro sobre "frenche pockes", doença que teria surgido no ano de 1496 (sic), e cujas características são compatíveis com as descrições contemporâneas da sífilis. Keiser (2003) identifica-a como tal. Os dois textos são acréscimos, e não partes integrantes do documento original do Regimento.

O destaque dado à sangria, num capítulo à parte, mostra o lugar central que ocupava a prática terapêutica. Tal primazia atravessa os séculos e justifica o pronunciamento de Curvo Semmedo (1720), que já sinaliza as discussões de revisão terapêutica no século XVIII:

Sendo as sangrias e as purgas os dous maiores remédios que tem a Medicina para curar a maior parte das doenças, que padecem os corpos, nem por isso se devem fazer inconsideradamente, como muitos fazem, sem causa, ou precisa necessidade ... porque vi morrer algumas pessoas, que tinham posto a natureza em costume de se sangrar e purgar todas as primaveras e outonos, sem que tivessem causa que os obrigasse a fazê-lo. (p. 577)

Huxham (1757) é um defensor da sangria, mas adverte: “I can by no Means approve of the promiscuous Use of Bleeding, so commonly practised in all Attacks of the Smallpox". ${ }^{20}$

O autor do Erário Mineral (Ferreyra, 1735), sempre favorável à adaptação dos velhos métodos aos novos momentos, faz também uma advertência:

Alguns autores de boa nota defendem as muitas sangrias, dizendo que o sangue é o tesouro da vida, e o bálsamo da natureza; e eu pela razão, e pela experiência, que tenho ... digo mais, que os muito sangrados nestas Minas não só ficam muito expostos a todas as enfermidades referidas, senão que todos, ou quase todos, ficam opilados, de tal sorte que não podem bulir-se, nem arrastar as pernas; e muitos vi, que por causa das sangrias perderam a vida. (p. 52)

Razão e experiência - a medicina do século XVIII aprofunda a rebeldia contra a teoria e a tradição, e cada vez mais se faz 'científica' (Lima, 1994). ${ }^{21}$ Recria então sua própria história, assumindo, como tantas outras disciplinas científicas, suas origens na 'racionalidade grega' do século V a.C. Mas a medicina que se assume hipocrática, desde a segunda metade do século XIX já não é capaz de compreender como 'racional' a teoria que não inclui o limite do corpo - o meio interno. 


\section{NOTAS}

1 Ver neste mesmo número a edição semi-diplomática e a tradução às páginas 833-39.

2 Ver, especialmente, Silva, Marinalva Freire da. Edición critica del Regimento Proueytoso contra ha Pestença (14961500?). Tesis doctoral en el Departamento de Filologia Romanica de la Facultad de Filosofia y Letras de la Universidad Complutense de Madrid, s.d.

3 Para o contexto histórico ver Prata de Souza, J., neste número.

4 Os efeitos das provisões do Marques de Pombal em relação à Universidade de Coimbra e à formação médica em Portugal são discutidos, por exemplo, por Alfredo Rasteiro, em e Ensino médico em Coimbra, 1131-2000. Coimbra: Quarteto, 1999.

5 Para os comentários sobre os autores em voga no período medieval, ver neste mesmo número Sousa \& Costa.

${ }^{6}$ Interessante discussão sobre os periódicos médicos no Brasil no século XIX, seu papel na institucionalização da medicina científica e sua relação com a higiene e o debate social, é vista em "Os periódicos médicos e a invenção de uma agenda sanitária para o Brasil (1827-43)”, de Luiz Otávio Ferreira. História, Ciências, Saúde Manguinhos, v. 6, n. 2, p. 331-51, 1999.

7 Pedro Luís Napoleão Chernoviz (1812-1881) publica na segunda metade do século XIX seu Dicionário de medicina popular e das ciências acessórias para o uso das famílias, com sucessivas edições.

8 O papel destas publicações é discutido, por exemplo, por Renata L. Rodrigues, em Mãe de família: discurso profilático contra a sífilis, Rio de Janeiro 1878-1889. Dissertação de mestrado, ENSP/Fiocruz, Rio de Janeiro, 2004.

9 Para discussão desta questão no Brasil, ver "Gomes Ferreira e os símplices da terra", de Maria Cristina C. Wissenbach. In: Furtado, J. F. (org.) Erário Mineral, v. 1. Rio de Janeiro: Fundação João Pinheiro/Fiocruz, 2002.

10 Medicamento simples é tal qual a natureza o criou. Medicamento composto é aquele que se compõe de duas ou mais coisas juntas por arte. Ver Pharmacopea Lusitana, Tratado I: em que se explicão os cânones de Mesue, p. 5-6.

11 Xarope (syrupus) simples é água com açúcar. Em geral, é um medicamento preparado pelo cozimento do sumo ou de outras partes das plantas, em algum líquido adoçado com açúcar ou mel. Esta a definição de Mesue e de Jacobo Manlio. Ver Pharmacopea Lusitana, p. 105.

12 “Nasce a Bugulosa nas planuras e nos lugares arenosos. Colhe-se no mês de julho. A que produz três frutos tratando-se com seu sumo e com sua raiz, tem bom resultado contra os calafrios da febre terçã e a que produz quatro, contra aqueles da quartã, especialmente no [ilegível]. Digo que também é útil para postemas. E semelhante ao verbasco e produz sua fronde baixa sobre a terra e [as folhas] negras, e ásperas, semelhantes à língua dos bois. As folhas metidas no vinho, alegram e confortam a alma."

13 Para uma discussão recente dos conceitos de saúde em Hipócrates, ver Draeger, A. C. F. Para além do logos: a peste de Atenas na obra de Tucídides. Dissertação de mestrado, Letras Clássicas/UFRJ, Rio de Janeiro, 2004 (orientador Henrique Cairus).

14 “O quarto [sinal] é quando as estrelas aparecem e parecem cair e sair de seus lugares: o que também significa que o ar está infectado e carregado de vapores infectados e venenosos."

15 “Da raiz superior vem e acontece a pestilência por virtude dos corpos de cima dos céus ... Da raiz inferior procede ... da privada que está acerca da câmera, ou de algum fedor particular ... [que] corrompe o ar em substância e qualidade."

16 "Podem afetar pessoas de todas as constituições, o que produzirá, é claro, grande variedade de sintomas."

17 “Especial atenção deve-se ter para com a constituição do paciente, e a constituição do ar, se queremos praticar com razão e sucesso em relação à varíola, e de fato, em relação a todas as outras desordens epidêmicas."

18 “Em uma palavra, cada caso particular necessita de um método particular, e o médico assistente deve mostrar seu julgamento em adaptá-lo adequadamente."

19 Para uma discussão sobre a circulação e as possíveis explicações sobre os locais de sangria, ver por exemplo Rebollo, R. A. "A difusão da doutrina da circulação do sangue: a correspondência entre William Harvey e Caspar Hofmann em maio de 1636". História, Ciências, Saúde - Manguinhos, v. 9, n. 3, p. 479-513, 2002.

20 "Eu não posso, de jeito algum, aprovar o uso promíscuo da sangria, praticado tão comumente em todos os ataques da varíola."

21 Lima, 1994, especialmente p. 170, aborda pontos importantes da discussão sobre a afirmação da ciência no século XVII. Ver também a bibliografia da autora. 


\section{REFERÊNCIAS BIBLIOGRÁFICAS}

Bernard, C.

1911

Broussais, F. J. V. 1828

Cairus, $\mathrm{H}$;

Ribeiro Jr., W. 2005

Canguilhem, G. 1990

Cardaillac, L. (org.) 1992

Cornford, F. M. 1981

Crisciani, C.; Agrimi, J. 1995

Dioscórides, $\mathrm{P}$. 1548

Ferreyra, Luis Gomes 1735

Grmek, Mirko D. 1995

Haller, A. 1761

Herlihy, D. 1997

Huxham, J. 1757

Jacquart, D. 1995

Jouanna, J. 1995

Keiser, G. R. 2003

Lima, N. T. 1994

Littré, E. 1839-1853.

Orta, G. 1891

Paynel, Thomas
La Science Expérimentale. [1865] Paris: J. B. Baillière et fils.

De l'irritation et de la folie. Paris: Mlle. Delaunay.

Textos Hipocráticos: o doente, o médico e a doença.

Rio de Janeiro: Ed. Fiocruz.

O normal e o patológico.

Rio de Janeiro: Forense Universitária.

Toledo, séculos XII-XIII. Muçulmanos, cristãos e judeus: o saber e a tolerância. Rio de Janeiro: Jorge Zahar.

Principium sapientiae: as origens do pensamento grego. Lisboa: Calouste Gulbenkian.

L'assistance dans la civilisation chrétienne médiévale. In: Grmek, Mirko D. (org.) Histoire de la pensée médicale en Occident: Antiquité et Moyen Âge. Paris: Seuil. p. 151-74.

Materia Medica. Matthioli, Pietro Andrea (ed.) Venegia: Valgrisi.

Erario Mineral.

Lisboa Occidental: Officina de Miguel Rodrigues.

Le concept de maladie. In: Grmek, Mirko D. (org.) Histoire de la pensée médicale en Occident: Antiquité et Moyen Âge. Paris: Seuil. p. 211-27.

Memoires sur la nature sensible et irritable des parties du corps animal. Lausanne: Marc - Mc. Bousquet \& Ce.

The Black Death and the transformation of the West. Cambridge: Harvard University Press.

An Essay on Fevers. 3. ed. London: J. Hinton.

La scolastique médicale. In: Grmek, Mirko D. (org.) Histoire de la pensée médicale en Occident: Antiquité et Moyen Âge. Paris: Seuil. p. 175-210.

La naissance de l'art médical occidental. In: GRMEK, Mirko D. (org.) Histoire de la pensée médicale en Occident: Antiquité et Moyen Âge. Paris: Seuil. p. 25-66.

Two medieval plague treatises and their afterlife in early modern England. Journal of the History of Medicine, v. 58, p. 292-324.

Valores sociais e atividade científica: um retorno à agenda de Robert Merton. In: Portocarrero, V. (org.) Filosofia, história e sociologia das ciências: abordagens contemporâneas. Rio de Janeiro: Ed. Fiocruz.

Oeuvres completes d'Hippocrate. $10 \mathrm{v}$. Paris: Academie Royale de Médecine.

Colóquios dos simples e drogas da India [Goa, 1563]. Edição dirigida e anotada pelo Conde de Ficalho. Lisboa: Imprensa Nacional.

A Moche Profitable Treatise Against the Pestilence.

[Cópia de original do British Museum.] 
Pita, J. R.

Roque, M. da C. 1979

Santo Antonio,

D. Caetano de

2000

Semmedo, João Curvo 1720

Sotres, P. G. 1995

Sournia, J. C.; Ruffie, J. 1984

Strohmaier, G. 1995
A Pharmacopea Lusitana de D. Caetano de Santo António ou quando se faz "divino o remédio humano." In: Santo António, D. Caetano de, Pharmacopea Lusitana, [1704] ed. fac-similada, Pita, João R. (org.) Coimbra: MinervaCoimbra. p. IX-XXV.

As pestes medievais européias e o Regimento proueytoso contra ha pestenença. Lisboa, Valentim Fernandes (1495-1496). Paris: Fundação Calouste Gulbenkian.

Pharmacopea Lusitana [1704], ed. fac-similada, Pita, João R. (org.) Coimbra: MinervaCoimbra.

Atalaia da vida contra as hostilidades da morte. Lisboa Occidental: Officina Ferreyrenciana.

Les régimes de santé. In: Grmek, Mirko D. (org.) Histoire de la pensée médicale en Occident: Antiquité et Moyen Âge. Paris: Seuil. p. 257-81.

As epidemias na história do homem.

Trad. Joel Goes. Lisboa: Edições 70.

Réception et tradition: la médecine dans le monde byzantin et arabe. In: Grmek, Mirko D. (org.) Histoire de la pensée médicale en Occident: Antiquité et Moyen Âge. Paris: Seuil. p. 123-49. 


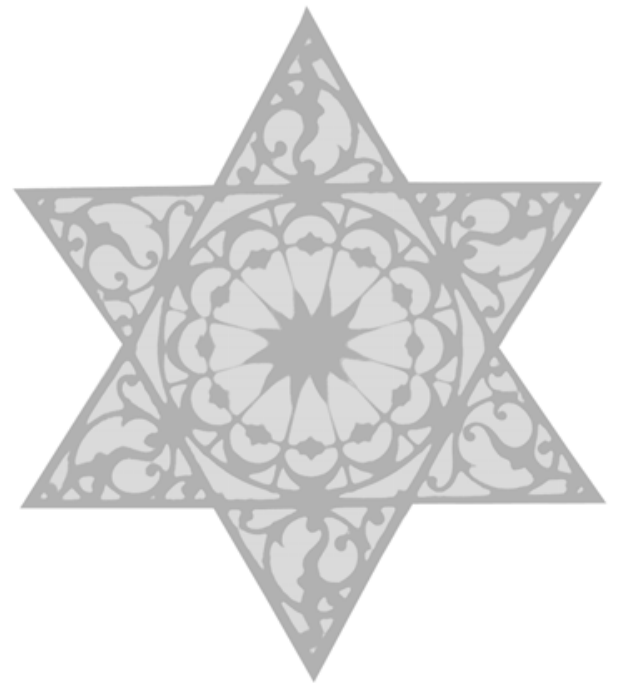

